\title{
Neonatal anatomical correction of transposition of the great arteries: non-invasive assessment of haemodynamic function up to four years after operation
}

\author{
JOHN L GIBBS, * SHAKEEL A QURESHI, † ROBIN MARTIN, NEIL WILSON, * \\ MAGDI H YACOUB, ROSEMARY RADLEY SMITH \\ From ${ }^{\star}$ Killingbeck Hospital, Leeds, $\uparrow$ Royal Liverpool Children's Hospital, Liverpool, and Harefield Hospital, \\ Middlesex
}

SUMMARY Intracardiac and great artery blood flow velocities were recorded by pulsed and은 continuous wave Doppler ultrasound in 18 children aged between eight months and four years(mean 25 months) who had undergone anatomical correction of transposition of the great arteries in $\subseteq$ the first month of life. Postoperative peak flow velocities across the mitral valve and in the ascending aorta were not significantly different from those in an age matched control population, but tricuspid flow velocities were higher than normal. Aortic regurgitation was detected in only one $e^{\circ}$ of the eighteen patients, a markedly lower frequency than that reported after two stage anatomical correction. Peak velocities in the pulmonary artery were higher than normal, and in most cases there was some degree of stenosis of the pulmonary artery at the site of anastomosis.

Little is known of the haemodynamic results of neonatal anatomical correction of transposition of the great arteries. Doppler ultrasound has allowed detailed non-invasive assessment of haemodynamic function in older children after both the single stage and two stage operations for anatomical correction. ${ }^{12}$ This study was performed to assess the haemodynamic results of the arterial switch operation performed in the first month of life and to determine whether recognised complications, such as aortic regurgitation, could be avoided by early correction.

\section{Patients and methods}

Eighteen children who had undergone the arterial switch operation for complete transposition of the great arteries with intact ventricular septum between the ages of one and 31 days (mean (SD) 10 (8) days) were studied with pulsed and continuous wave Doppler ultrasound. In all cases the pulmonary artery anastomosis was direct and to the left of the aorta. The manoeuvre described by Lecompte et $a l^{\beta}$

Requests for reprints to Dr John L Gibbs, The Noninvasive Heart Unit, Killingbeck Hospital, York Road, Leeds LS14 6UQ.

Accepted for publication 16 February 1988 was used in 15 children and in the remaining three⿳亠丷厂 anastomosis was possible without this procedure. The mean (SD) interval between operation and noninvasive investigation was 25 (14) months. The children constituted $64^{\circ}{ }_{0}$ of all those who had $\vec{\sigma}^{\circ}$ neonatal anatomical correction at Harefield Hospital up to the time of the study, and they were selected for investigation solely on grounds of their being able to attend at the time of the study.

Flow velocities were recorded distal to each of the four cardiac valves and, whenever possible, were also응 measured in the proximal branch pulmonary arteries. $D$ Peak flow velocities were measured for at least three? cardiac cycles and the average of these values was recorded. Pressure drops, where appropriate, were calculated by the modified Bernoulli equation (by ${ }_{0}$ multiplying by four the difference between the squares of the velocities either side of an obstruc- -0 tion). The examination included systematic search to ing for regurgitant jets in both atria and both ventricular outflow tracts, as well as pulsed wave? recordings of ascending aortic flow to detect any맘 diastolic flow reversal caused by aortic regur-웅 gitation. ${ }^{45} \mathrm{We}$ compared the results with those of $32 \mathrm{D}$ age matched normal children drawn from a large study of normal blood flow velocities. ${ }^{6}$ 
STATISTICAL ANALYSIS

We used the Mann and Whitney $U$ test to assess differences from the normal peak mitral, tricuspid, aortic, and pulmonary artery flow velocities because values in the postoperative patients were not normally distributed. We used Fisher's exact test to compare the frequency of aortic regurgitation in the present study population with that in an earlier study of children who had undergone two stage anatomical repair of complete transposition. ${ }^{2}$

\section{Results}

\section{ATRIOVENTRICULAR FLOW VELOCITIES}

Table 1 shows the peak flow velocities across the mitral and tricuspid valves. Flow velocities across the mitral valve were not significantly different from normal, but flows across the tricuspid valve were higher than normal. There was no significant relation between either peak mitral flow velocity and age or tricuspid flow velocity and age. No mitral regurgitation was detected, but in five patients there were low intensity tricuspid regurgitant signals that resembled those found in normal subjects. ${ }^{7}$

\section{AORTIC FLOW VELOCITIES}

Peak flow velocities in the ascending aorta (table 1) were slightly higher than those in the normal subjects, but this difference was not statistically significant. Aortic regurgitation was detected in only one $\left(5 \cdot 5^{\circ}{ }_{0}\right)$ of the children. This did not seem to be haemodynamically important because it did not produce any reversal of diastolic flow in the ascending aorta.

\section{PULMONARY ARTERY FLOW VELOCITIES}

The mean of the peak flow velocities in the main pulmonary artery was $2.9 \mathrm{~m} / \mathrm{s}$, equivalent to a peak pressure drop of approximately $34 \mathrm{~mm} \mathrm{Hg}$. Peak velocities were within $3 \mathrm{SD}$ of the normal mean in only two children and the maximum calculated pressure drop in the main pulmonary artery was 185 mm Hg (table 2).

We were able to sample flow velocities distal to the bifurcation of the left pulmonary artery in five of the 18 children. In three there was an increase in velocity at the bifurcation caused by stenosis of the proximal branch (with calculated pressure drops of 24, 29, and $36 \mathrm{~mm} \mathrm{Hg}$ ). These three children had overall pressure drops between the right ventricular outflow tract and the left pulmonary artery of 36,48 , and 64 $\mathrm{mm} \mathrm{Hg}$ respectively, indicating some degree of coexistent stenosis at the level of the anastomosis. The pulmonary arterial pressure drops in the remaining cases seemed to be solely at the anastomotic site. There was no relation between the
Table 1 Ages and peak blood flow velocities after the neonatal arterial switch operation and in the normal subjects

\begin{tabular}{lccl}
\hline & After operation & Normal & $p$ \\
\hline No & 18 & 32 \\
Mean (SD) age in years & $2 \cdot 1(1 \cdot 2)$ & $2 \cdot 2(1 \cdot 5)$ & NS \\
\multicolumn{4}{c}{$\begin{array}{c}\text { Median }(\text { range) peak flow } \\
\text { velocity in cm/s: }\end{array}$} \\
Mitral & $88(62-117)$ & $80(48-124)$ & NS \\
Tricuspid & $66(48-103)$ & $58(41-114)<0.04$ \\
Aorta & $118(70-260)$ & $106(73-155)$ & NS \\
Pulmonary artery & $250(120-680)$ & $86(56-119)<0.001$ \\
\hline
\end{tabular}

Table 2 Peak flow velocities in the main and left branch pulmonary arteries

\begin{tabular}{|c|c|c|}
\hline \multirow[b]{2}{*}{ Case No } & \multicolumn{2}{|c|}{$\begin{array}{l}\text { Peak flow velocity in } \mathrm{cm} / \mathrm{s} \\
\text { Site }\end{array}$} \\
\hline & $M P A$ & $L P A$ \\
\hline 1 & 294 & - \\
\hline 2 & 140 & - \\
\hline 3 & 170 & 346 \\
\hline 4 & 260 & 260 \\
\hline 5 & 240 & - \\
\hline 6 & 120 & - \\
\hline 7 & 150 & - \\
\hline 8 & 380 & 392 \\
\hline 9 & 290 & - \\
\hline 10 & 680 & - \\
\hline 11 & 295 & - \\
\hline 12 & 240 & - \\
\hline 13 & 295 & 400 \\
\hline 14 & 670 & - \\
\hline 15 & 240 & - \\
\hline 16 & 238 & \\
\hline 17 & 398 & - \\
\hline & 170 & 300 \\
\hline Median & 250 & \\
\hline Mean (SD) & $293(158)$ & \\
\hline
\end{tabular}

Sampling of the left pulmonary artery was possible in only five children. MPA, main pulmonary artery; LPA, left pulmonary artery.

severity of pulmonary artery stenosis and the time since surgical correction. In seven children we detected weak signals of pulmonary regurgitation, like those seen in normal subjects. ${ }^{7}$

\section{Discussion}

\section{ATRIOVENTRICULAR FLOW VELOCITIES}

Anatomical correction by single stage operation in the neonatal period and later in life ${ }^{2}$ is associated with normal peak mitral flow velocities. After the two stage operation, however, mitral flow velocities are increased, probably because of subtle abnormalities in left ventricular architecture. ${ }^{2-10}$ Tricuspid flow velocities were higher than normal both after two stage $^{2}$ and single stage repair, and it seems that these abnormalities (the importance of which is uncertain) are present even if correction is performed neonatally. 
Table 3 Frequency of aortic regurgitation after neonatal anatomical correction and after two stage anatomical correction

\begin{tabular}{lcc}
\hline & \multicolumn{2}{l}{ Aortic regurgitation $(\%)$} \\
\cline { 2 - 3 } Type of repair & Present & Absent \\
\hline $\begin{array}{l}\text { Neonatal } \\
\mathrm{n}=18\end{array}$ & $1(5.5)$ & $17(94.5)^{\star}$ \\
$\begin{array}{l}\text { nwo stage } \\
\mathrm{n}=18^{2}\end{array}$ & $10(55.5)$ & $8(44.5)^{\star}$ \\
\hline${ }^{\star} \mathrm{p}<0.002$. & & \\
\end{tabular}

AORTIC FLOW VELOCITIES

Flow velocities in the ascending aorta are normal after the neonatal switch operation. This is in contrast with the two stage repair, after which they are significantly lower than normal, probably as a result of aortic root dilatation. ${ }^{2}$ One of the most striking findings after neonatal correction was the low frequency of aortic regurgitation compared with the two stage anatomical repair (table 3). Trivial aortic regurgitation was detected in only $5.5 \%$ of children who had neonatal repair, whereas in an earlier study we found aortic regurgitation in $55 \%$ of patients after the two stage operation. ${ }^{2}$ This result has implications for the aetiology of aortic regurgitation after the arterial switch operation. It has been suggested that pulmonary regurgitation may occur preoperatively in patients with complete transposition and that the posterior semilunar valve is inherently incompetent before correction in some patients. " The low frequency of aortic regurgitation after neonatal repair shown in this study, however, is conclusive evidence that the definitive aortic valve is potentially competent in nearly all cases. In terms of the risk of the development of aortic regurgitation, therefore, it seems better to perform anatomical correction in the neonatal period rather than later.

\section{PULMONARY ARTERY FLOW VELOCITIES}

Flow velocities in the pulmonary artery are almost invariably high after the neonatal switch operation, and there is important stenosis at the site of anastomosis in some children. Further stenosis at the origins of the branch pulmonary arteries was detected in three cases, and this feature may have been underestimated as it is technically difficult to ensure close alignment of the Doppler beam with the direction of blood flow in the branch pulmonary arteries. The findings in this study confirmed our previous experience that in some cases there is stenosis at the origin of the left pulmonary artery as well as main pulmonary artery stenosis. Although there can be pulmonary artery stenosis at the site of anastomosis after later single stage and two stage repair, in our experience obstruction at this level is more common and more severe after neonatal correction.

Neonatal anatomical correction of simple trans- position of the great arteries gives better haemody- $\frac{T}{D}$ namic function of the aortic valve and avoids the $\stackrel{N}{7}$ abnormalities of left ventricular filling velocities seen $C$ after two stage repair. None the less, the high frequency of right ventricular outflow obstruction after neonatal correction remains a problem that requires further investigation and modification of surgical technique.

We thank Mrs Wilmar Dean for her administrative assistance and PPG Hellige Ltd for their technical support.

\section{References}

1 Gibbs JL, Qureshi SA, Grieve L, Webb C, Radley Smith R, Yacoub MH. Doppler echocardiography after anatomical correction of transposition of the great arteries. Br Heart $J$ 1986;56:67-72.

2 Gibbs JL, Qureshi SA, Wilson N, Radley Smith R, Yacoub MH. Doppler echocardiographic comparison of haemodynamic results of one and two stage anatomic correction of transposition of the great arteries. Int J Cardiol 1988;18:85-92.

3 Lecompte Y, Zannini L, Hazan E et al. Anatomical correction of transposition of the great arteries: a new technique without use of prosthetic conduit. $J$ Thorac Cardiovasc Surg 1981;82:629-31.

4 Goldberg SJ, Allen HD. Quantitative assessment by Doppler echocardiography of pulmonary or aortic regurgitation. Am J Cardiol 1985;56:131-5.

5 Touche T, Prasquier R, Nitenberg A, de Zuttere D, Gourgon R. Assessment and follow up of patients with aortic regurgitation by an updated Doppler echocardiographic measurement of the regurgitant fraction in the aortic arch. Circulation 1985;72: 819-24.

6 Wilson N, Goldberg SJ, Dickinson DF, Scott O. Normal intracardiac and great artery blood velocity measurements by pulsed Doppler echocardiography. Br Heart J 1985;53:451-8.

7 Kostucki W, Vandenbossche J, Friart A, Englert M. Pulsed Doppler regurgitant flow patterns of normal valves. Am J Cardiol 1986;58:309-13.

8 Heintzen PH, Lange PE, Wessel A, Radley Smith R, Bernhard HA, Yacoub MH. Angiocardiographic and echocardiographic evaluation of ventricular geometry and function before and after two stage anatomic correction of complete transposition of the great arteries with intact ventricular septum. Pediatr Cardiol 1983;4:123-30.

9 Arensman FW, Radley Smith R, Yacoub MH, et al. Catheter evaluation of left ventricular shape and function one or more years after anatomical correction of transposition of the great arteries. Am J Cardiol 1983;52:1079-83.

10 Smith A, Wilkinson JL, Anderson RH, Arnold R, Dickinson DF. Architecture of the ventricular mass and atrioventricular valves in complete transposition with intact septum compared with the normal: 1 . The left ventricle, mitral valve and interventricular septum. Pediatr Cardiol 1986;6:253-7.

11 Qureshi SA, Ettedgui JA, Jones ODH. Pulmonary regurgitation in transposition of the great arteries. $\mathrm{Br}$ Heart J 1987;57:199-201. 